${ }^{1}$ Dept of Pulmonary Physiology and Sleep Medicine, Sir Charles Gairdner Hospital, Nedlands, Australia. ${ }^{2}$ School of Anatomy, Physiology and Human Biology, University of Western Australia, Australia. ${ }^{3}$ Centre for Neonatal Research and Education, School of Paediatrics and Child Health, University of Western Australia, Crawley, WA, Australia. ${ }^{4}$ Dept of Pathology and Laboratory Medicine, University of British Columbia James Hogg Research Centre, Institute for Heart and Lung Health, St. Paul's Hospital, Vancouver, Canada. ${ }^{5}$ School of Medicine and Pharmacology, University of Western Australia, Australia.

Correspondence: Robyn Jones, Department of Pulmonary Physiology and Sleep Medicine, Sir Charles Gairdner Hospital, Nedlands, Western Australia 6009. E-mail: robyn.jones@health.wa.gov.au

Received: June 222015 | Accepted after revision: Feb 042016 | First published online: March 172016

Support statement: Funding provided by the National Health and Medic al Research Council (NHMRC) of Australia (513842 and 1063068) and Sir Charles Gairdner and Osborne Park Health Care Group Research Advisory Committee and Charlies Foundation for Research (APP1045674). Peter B. Noble's salary was provided by a Career Development Fellowship from the NHMRC of Australia (1045824). Funding information for this article has been deposited with FundRef.

Conflict of interest: Disclosures can be found alongside the online version of this article at erj.ersjournals.com

Acknowledgements: Funding provided by the National Health and Medical Research Council (NHMRC) of Australia (513842 and 1063068) and Sir Charles Gairdner and Osborne Park Health Care Group Research Advisory Committee and Charlies Foundation for Research (APP1045674). Peter B. Noble's salary was provided by a Career Development Fellowship from the NHMRC of Australia (1045824).

\title{
References
}

1 Hogg JC. Pathophysiology of airflow limitation in chronic obstructive pulmonary disease. Lancet 2004; 364: 709-721.

2 James AL, et al. Airway smooth muscle thickness in asthma is related to severity but not duration of asthma. Eur Respir J 2009; 34: 1040-1045.

3 Ebina M, Takahashi T, Chiba T, et al. Cellular hypertrophy and hyperplasia of airway smooth muscles underlying bronchial asthma. A 3-D morphometric study. Am Rev Respir Dis 1993; 148: 720-726.

4 Woodruff PG, Dolganov GM, Ferrando RE, et al. Hyperplasia of smooth muscle in mild to moderate asthma without changes in cell size or gene expression. Am J Respir Crit Care Med 2004; 169: 1001-1006.

5 James AL, Elliot JG, Jones RL, et al. Airway smooth muscle hypertrophy and hyperplasia in asthma. Am J Respir Crit Care Med 2012; 185: 1058-1064.

6 Ebina M, Yaegashi H, Chiba R, et al. Hyperreactive site in the airway tree of asthmatic patients revealed by thickening of bronchial muscles. A morphometric study. Am Rev Respir Dis 1990; 141: 1327-1332.

7 Jones RL, Elliot JG, James AL. Estimating airway smooth muscle cell volume and number in airway sections. Sources of variability. Am J Respir Cell Mol Biol 2014; 50: 246-252.

8 Hogg JC, Chu F, Utokaparch S, et al. The nature of small-airway obstruction in chronic obstructive pulmonary disease. N Engl J Med 2004; 350: 2645-2653.

9 Kranenburg AR, Willems-Widyastuti A, Moori WJ, et al. Enhanced bronchial expression of extracellular matrix proteins in chronic obstructive pulmonary disease. Am J Clin Pathol 2006; 126: 725-735.

10 Annoni R, et al. Extracellular matrix composition in COPD. Eur Respir J 2012; 40: 1362-1373.

11 Buist AS, McBurnie MA, Vollmer WM, et al. International variation in the prevalence of COPD (the BOLD Study): a population-based prevalence study. Lancet 2007; 370: 741-750.

12 James AL, Palmer LJ, Kicic E, et al. Decline in lung function in the Busselton health study: the effects of asthma and cigarette smoking. Am J Respir Crit Care Med 2005; 171: 109-114.

13 Decramer M, Janssens W, Miravitlles M. Chronic obstructive pulmonary disease. Lancet 2012: 1341-1351.

14 Sears MR, Greene JM, Willan AR, et al. A longitudinal, population-based, cohort study of childhood asthma followed to adulthood. N Engl J Med 2003; 349: 1414-1422.

15 Hardin M, Silverman EK, Barr RG, et al. The clinical features of the overlap between COPD and asthma. Respir Res 2011; 12: 127.

\section{An outreaching model of tertiary difficult asthma care reduces adverse asthma outcomes and healthcare utilisation costs}

To the Editor:

Difficult asthma is a heterogeneous state, pragmatically defined by the British Thoracic Society (BTS) as "persistent symptoms and/or frequent exacerbations despite treatment at step 4 or step 5 treatment" $[1,2]$. 
It is frequently associated with aggravating comorbidities, causes significant morbidity and healthcare costs, and requires rigorous systematic assessment and treatment approaches [3-7]. Though few exist, referral to a specialist centre with appropriate multidisciplinary expertise and supporting technical resource is recommended [8]. It is unclear whether such care can be effectively delivered in a peripheral healthcare setting. We report initial outcomes of such a care pathway on the Isle of Wight (IOW), UK.

An outreach difficult asthma clinic was initiated at a district general hospital (St Mary's Hospital, IOW, UK) within an existing outreach allergy clinic. A difficult asthma multidisciplinary team was established combining local nursing, physiotherapy, dietetic and psychology resources with a visiting asthma and allergy consultant from the regional difficult asthma centre. Management followed a structured assessment with implementation of appropriate treatment as needed plus emphasis on self-management strategies, education and inhaler technique checks. Clinical outcomes were assessed in the first 17 referred patients. Approval was obtained from an independent ethics committee (Ethics and Research Governance committee) at the University of Southampton (Southampton, UK) (ethics ID 7511).

Data were collated from clinical data recorded during routine clinical assessment at a referral point (baseline) and after 18 months of being under the difficult asthma clinic (post-care). Core baseline data collection included asthma treatment, relevant physical and psychological/psychiatric comorbidities (defined clinically), spirometry, skin prick test (SPT) and relevant blood tests. Adherence was noted from prescription pick-up data and clinical impression. Spirometry was measured using a portable machine (Vitalograph Ltd, Buckingham, UK). SPT was performed with common aeroallergens (house dust mite, cat, dog, grass, tree, feathers and mould spores; ALK-Abello, Hørsholm, Denmark) and atopy defined by SPT weal diameter size $\geqslant 3 \mathrm{~mm}$.

Healthcare utilisation (HCU), including asthma-related general practitioner visits, accident and emergency (A\&E) visits, inpatient days and intensive therapy unit (ITU) days, and changes in treatment were compared for the preceding 12 months between baseline and post-care points. Courses of oral steroid (OCS) therapy for asthma exacerbations varied from 30 to $40 \mathrm{mg}$ prednisolone per day while duration varied from 3 to 10 days. We therefore standardised acute OCS therapy to number of days on equivalent to $40 \mathrm{mg}$ prednisolone per day dose. Data were analysed using SPSS version 19 (IBM, Armonk, NY, USA). Paired sample t-tests and McNemar's test were used for statistical comparisons between pre- and post-care assessments with a significance value of $\mathrm{p}<0.05$.

The first 17 BTS-defined difficult asthma patients referred to the clinic were assessed in this study. Patients were typically female $(82.4 \%)$, in the fifth decade of life, with childhood-onset asthma (64.7\%). Common baseline comorbidities included rhinitis $(94.0 \%)$, atopy $(82.4 \%)$, overweight/obesity $(76.5 \%$, mean body mass index $30.59 \mathrm{~kg} \cdot \mathrm{m}^{-2}$ ), gastro-oesophageal reflux disease $(64.7 \%)$, dysfunctional breathing (47.1\%), salicylate sensitivity (41.7\%) and psychological comorbidity (35.3\%). Current smoking was recorded in $11.8 \%$ and past smoking in 35.3\% with a mean 13.7-pack-year history among current or past smokers. Mean forced expiratory volume in $1 \mathrm{~s}$ was $2.28 \mathrm{~L}$ ( $76.7 \%$ predicted) and did not change significantly over the study period. Self-management plan use rose from $0 \%$ to $100 \%$ between the baseline and post-care assessments. Referral to a physiotherapist for dysfunctional breathing was made for nine $(52.9 \%)$ patients and to a psychologist for psychological comorbidities in five (29.4\%). Six patients with suspected salicylate sensitivity had dietetic review.

At referral, $47.1 \%$ of patients were on BTS step 4 and $52.9 \%$ on step 5 treatment. Home nebulisers were used in $58.8 \%$ and subcutaneous terbutaline in $23.5 \%$ at baseline; the latter halved after 18 months. Clinic input led to increased use of long-acting $\beta$-agonists, leukotriene receptor antagonist, nasal steroid and tiotropium. All subjects were using inhaled corticosteroids at referral with $11.8 \%$ on "ultrafine particle" inhalers (Qvar (Teva, Castleford, UK), ciclesonide (Takeda, Woodburn Green, UK) or Fostair (Chiesi, Manchester, UK)). That increased to $88.3 \%$ after 18 months, with use of ciclesonide increasing from $5.9 \%$ to $82.4 \%$. At 18 months, $52.9 \%$ of patients were on ciclesonide plus combination inhalers, either Seretide (GlaxoSmithKline, Uxbridge, UK) (fluticasone $250 \mu \mathrm{g} / \mathrm{salmeterol} 25 \mu \mathrm{g} ; 17.6 \%$ ), Symbicort (AstraZeneca, Luton, UK) (budesonide $200 \mu \mathrm{g} /$ formoterol $6 \mu \mathrm{g} ; 23.5 \%$ ) and Fostair (beclomethasone $100 \mu \mathrm{g} /$ formoterol $6 \mu \mathrm{g} ; 23.5 \%)$. Use of rhinitis treatment increased from $43 \%$ to $86 \%$ after 18 months.

Daily maintenance OCS use reduced from $52.9 \%$ to $42.1 \%$ after 18 months (table 1). Mean baseline maintenance OCS dose was $15.56 \mathrm{mg}$ (95\% CI $8.78-22.33 \mathrm{mg}$ ) versus $7.22 \mathrm{mg}$ (95\% CI 3.33-11.12 mg) after 18 months. No patients were treated with oral steroid-sparing agents or omalizumab during this study. An annual average reduction of 26.27 days in $40 \mathrm{mg}$ prednisolone equivalent use was achieved at 18 months. A significant reduction in annual HCU was found at the post-care point (figure 1). Annual general practitioner visits reduced by mean of 3.8 (95\% CI 2.4-5.2, p<0.001), A\&E visits reduced by 1.9 (95\% CI 0.7-3.1, p=0.004), hospital bed days decreased by 7.7 (95\% CI 4.4-11.0, p<0.001) and ITU days decreased by 1.5 ( $95 \%$ CI $0.2-2.8, \mathrm{p}=0.024)$. At the secondary care (A\&E, inpatient stay and ITU stay) level, annual net savings of $£ 52000$ were realised for this patient cohort. 
TABLE 1 Oral corticosteroid (OCS) maintenance dose for those on maintenance prednisolone therapy

\begin{tabular}{|c|c|c|}
\hline & $\begin{array}{c}12 \text { months before } \\
\text { referral }\end{array}$ & $\begin{array}{l}12 \text { months after } \\
6 \text { months in care }\end{array}$ \\
\hline Patients & 17 & 17 \\
\hline Patients on daily OCS n (\%) & $9(52.9)$ & $7(41.2)$ \\
\hline Daily OCS dose $\mathrm{mg}$ & $15.56(8.78-22.33)$ & $7.22(3.33-11.12)$ \\
\hline Patients on $30 \mathrm{mg}$ & 1 & 0 \\
\hline Patients on $25 \mathrm{mg}$ & 1 & 0 \\
\hline Patients on $20 \mathrm{mg}$ & 2 & 0 \\
\hline Patients on $15 \mathrm{mg}$ & 1 & 1 \\
\hline Patients on $10 \mathrm{mg}$ & 2 & 4 \\
\hline Patients on $5 \mathrm{mg}$ & 2 & 2 \\
\hline Patients not on OCS & 8 & 10 \\
\hline Number of days $40 \mathrm{mg}$ OCS given over 12 -month period ${ }^{\#}$ & $37.59(19.7-55.5)$ & $11.32(4.5-18.2)$ \\
\hline
\end{tabular}

A systematic approach to severe asthma care that confirms asthma diagnosis, defines phenotype, optimises pharmacotherapy, and addresses nonadherence and aggravating comorbidities affords optimal management $[3,4]$. While that care is the traditional preserve of a tertiary centre, the outreach model assessed in this study demonstrated significant reduction in asthma healthcare utilisation and associated costs in parallel with reduced systemic steroid use. Access to more specialised resources including induced sputum analysis, bronchoscopy with biopsy/lavage, exhaled nitric oxide measures and surrogates of adherence like prednisolone assay was lacking in the outreach clinic. While such resources are helpful, our outcomes suggest that such gaps were not necessarily detrimental.

The definition of difficult asthma used in this study is comparable to that recently assessed in the BTS Difficult Asthma Registry [6, 9, 10]. Baseline characterisation of our clinic cohort was similar to the BTS Registry. While our baseline hospital admissions were relatively high, follow-up assessment showed significant reductions in acute HCU. These reductions mirrored those shown by BTS Difficult Asthma Registry review [10]. Earlier review of the BTS registry also demonstrated improvements in asthma outcomes but associated with increased oral steroid use [6]. Our outreach clinic saw significant reduction in both maintenance dose of oral prednisolone and acute courses of oral steroid but not the proportion of subjects on maintenance prednisolone. That is similar to more recent tertiary centre findings [10].

Multiple factors contributed to the improved outcomes in this study. Difficult Asthma rarely occurs in isolation and treating aggravating comorbidities can significantly improve the "Difficult Breathing Syndrome" that such patients suffer. A strong multidisciplinary approach with basic education, inhaler technique review, universal use of personal asthma action plans, encouragement to adhere to therapy and awareness of how comorbidities influence symptoms were important facets of the outreach clinic. Formal patient-centred assessment of outcomes, such as ACQ or AQLQ, has shown significant improvement in response to tertiary centre asthma care [11]. Weaknesses of our study include that we did not universally collect such data during

FIGURE 1 Changes in acute healthcare utilisation with clinic management, comparing the healthcare utilisation for last 12 months at referral and last 12 months after 18 months of care under the difficult asthma clinic. GP: general practitioner, A\&E: accident and emergency; IP: inpatient; ITU: intensive therapy unit. $p$-values from paired-sample t-test. $* * *: p<0.001 ;{ }^{\#}: p=0.004 ;$ १: $\mathrm{p}=0.024$.

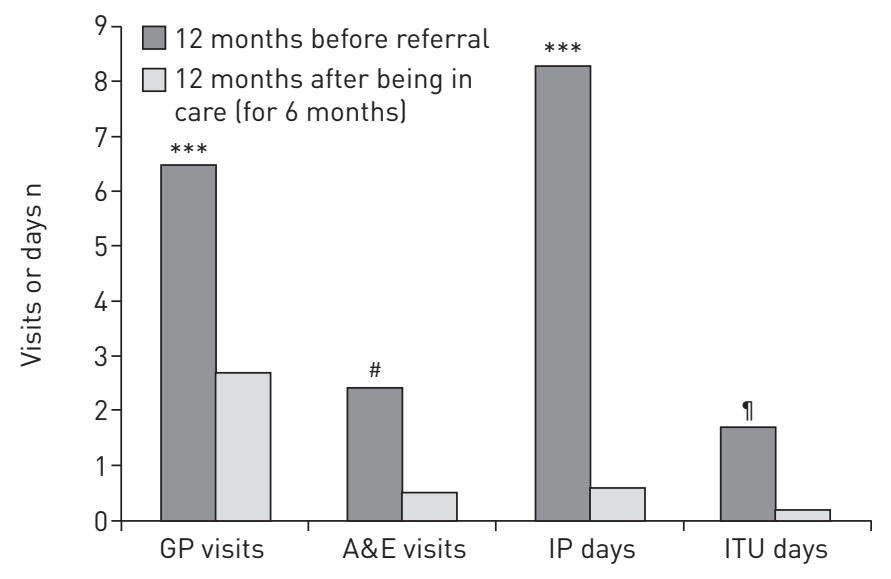


the study period, the retrospective nature and the absence of validated adherence measures such as the MARS-A questionnaire. Achieving good adherence and assessing that remains a holy grail in difficult asthma care. A core component of our approach was centred on embedding self-management strategies, checking inhaler use and correct technique, and it is very likely those led to improved adherence.

This study observed a considerable switch to high-dose ciclesonide plus combination inhaler, which would have resulted in a significant increase in inhaled steroid load. However, as this approach was instituted alongside many others in our patients, it is not possible to draw conclusions on its specific effect. It is likely that the benefits reaped in our clinic reflected the multifactorial and holistic intervention strategy implemented for a "difficult breathing syndrome" rather than just asthma therapies in isolation.

Our "top down" approach certainly delivered substantial patient benefit. It is worth considering whether some of our patients may have benefited from a "bottom up" approach to better asthma care earlier in their patient journey. Evidence for primary-care based approaches such as the SIMPLES approach is emerging in that context [11].

In conclusion, outreaching specialist care could deliver benefits for patients in locations far from tertiary centres, whilst also providing potential cost savings. Outreaching models of difficult asthma care as part of evolving "networked specialist care" merit consideration.

\section{@ERSpublications}

Outreaching specialist asthma care can significantly benefit patients with difficult asthma in peripheral settings http://ow.ly/YClKM

Veeresh K. Patil ${ }^{1,2}$, Christine Townshend ${ }^{1,3}$, Frances Mitchell ${ }^{1}$ and Ramesh J. Kurukulaaratchy ${ }^{1,2}$

${ }^{1}$ The David Hide Asthma and Allergy Research Centre, St Mary's Hospital, Isle of Wight, UK. ${ }^{2}$ Clinical and Experimental Sciences, University of Southampton, Southampton, UK. ${ }^{3}$ University of Southampton, Southampton, UK.

Correspondence: Ramesh J. Kurukulaaratchy, The David Hide Asthma and Allergy Research Centre, St Mary's Hospital, Isle of Wight, PO30 5TG, UK. E-mail: r.j.kurukulaaratchy@soton.ac.uk

Received: Sept 182015 | Accepted after revision: Feb 142016 | First published online: March 232016

Conflict of Interest: None declared

Acknowledgements: We would like to thank all the staff at the David Hide Asthma and Allergy Research Centre, Isle of Wight, UK.

\section{References}

1 Chung KF, Wenzel SE, Brozek JL, et al. International ERS/ATS guidelines on definition, evaluation and treatment of severe asthma. Eur Respir J 2014; 43: 343-373.

2 British Thoracic Society, Scottish Intercollegiate Guidelines Network. British guideline on the management of asthma. Thorax 2014; 69: Suppl. 1, 1-192.

3 Heaney LG, Conway E, Kelly C, et al. Predictors of therapy resistant asthma: outcome of a systematic evaluation protocol. Thorax 2003; 58: 561-566.

4 Robinson DS, Campbell DA, Durham SR, et al. Systematic assessment of difficult-to-treat asthma. Eur Respir J 2003; 22: 478-483.

5 Aldington S, Beasley R. Asthma exacerbations. 5: assessment and management of severe asthma in adults in hospital. Thorax 2007; 62: 447-458.

6 Sweeney J, Brightling CE, Menzies-Gow A, et al. Clinical management and outcome of refractory asthma in the UK from the British Thoracic Society Difficult Asthma Registry. Thorax 2012; 67: 754-756.

7 Urso DL, Vincenzo D, Pignataro E, et al. Diagnosis and treatment of refractory asthma. Eur Rev Med Pharmacol Sci 2008; 12: 315-320.

8 Bratton DL, Price M, Gavin L, et al. Impact of a multidisciplinary day program on disease and healthcare costs in children and adolescents with severe asthma: a two-year follow-up study. Pediatr Pulmonol 2001; 31: 177-189.

9 O'Neill S, Sweeney J, Patterson CC, et al. The cost of treating severe refractory asthma in the UK: an economic analysis from the British Thoracic Society Difficult Asthma Registry. Thorax 2015; 70: 376-378.

10 Gibeon D, Heaney LG, Brightling CE, et al. Dedicated severe asthma services improve healthcare utilisation and quality of life. Chest 2015; 148: 870-886.

11 Ryan D, Murphy A, Stallberg B, et al. 'SIMPLES': a structured primary care approach to adults with difficult asthma. Prim Care Respir J 2013; 22: 365. 